\title{
Outcome of major depression in Ethiopia
}

\author{
Population-based study
}

SOUCI MOGGA, MARTIN PRINCE, ATALAY ALEM, DEREGE KEBEDE, ROBERT STEWART, NICK GLOZIER and MATTHEW HOTOPF

\section{Background The outcome and impact of major depression in developing countries are not clear.}

\begin{abstract}
Aims To describe the outcome of major depression and compare the disability and patterns of service use among different outcome groups.
\end{abstract}

Method In a case cohort study, nested within a population-based survey of 68000 participants using the Composite International Diagnostic Interview (CIDI), 300 participants were randomly selected from those with current major depression and 300 from those with no lifetime history. Participants were re-interviewed after 18-62 months to ascertain current diagnosis, psychological symptoms, disability and use of health services.

Results Of participants with major depression at baseline $26 \%$ also met criteria for major depression at follow up. Mortality ratio standardised for age and gender was 3.55 (95\% Cl 1.97 to 6.39). All indices of measure of disability were significantly higher in the persistently depressed group compared with the completely recovered group. Participants who had recovered partially resembled participants with persistent depression. Two-thirds of those with persistent depression had not sought any help.

Conclusions Major depression was associated with mortality and disability. Those with residual symptoms remained disabled. Help-seeking was unusual.

Declaration of interest None. Funding detailed in Acknowledgements.
The Global Burden of Disease (GBD) report of the World Health Organization (WHO) provides the best available evidence on the relative impact of health problems worldwide (Murray \& Lopez, 1996). The marked association of depression with disability, high levels of health service use (Lepine et al, 1997; Kessler et al, 2003) and high mortality risk (Lee \& Murray, 1988) have been reported in North America and Europe. Low- and middleincome countries lack resources and most people with mental disorders do not receive treatment. The outcome of major depression and its impact in such communities is not known. Ethiopia, with a population of 70 million (Central Statistics Authority, 2000 ), has health service coverage of $61 \%$ (Ethiopian Ministry of Health, 2002) and 9 psychiatrists.

Our aim was to describe the outcome of major depression, the associated disability and patterns of service use among different outcome groups, in a naturalistic, prospective study of a representative case cohort in an Ethiopian community.

\section{METHOD}

\section{Setting}

The study was carried out in the Meskan and Mareko district in Ethiopia. The estimated size of the district is $797 \mathrm{~km}^{2}$. It has a total population of 227000 (Office of Population and Housing Census Commission, 1994) and is located $135 \mathrm{~km}$ south of the capital city, Addis Ababa. As part of an ongoing study of the course and outcome of schizophrenia and bipolar affective disorder, 68378 individuals aged 15-49 years completed the Composite International Diagnostic Interview (CIDI; World Health Organization, 1997) in a cross-sectional house-to-house screening survey between March 1998 and May 2001 (Kebede et al, 2003a,b). This survey population, excluding 9 inaccessible sub-districts, formed the base population for the prospective study described here $(n=56441)$.

\section{Design}

The case cohort study was nested within a population-based survey. Data from the affective disorder module of the initial CIDI survey were used to identify two sampling frames. 'Major depression' included those identified by CIDI as having major depression in the past 12 months at the time of the baseline survey $(n=694)$. 'No depression' included all those in the baseline survey who did not meet CIDI criteria for any lifetime depression ( $n=54173)$. Using the Statistical Package for the Social Sciences (SPSS) version $\mathbf{1 1 . 0}$ for Windows, 300 participants were selected at random from each sampling frame defined at baseline and then approached for re-assessment 18 to 52 months after baseline.

\section{Measures}

\section{Sociodemographic status}

In the baseline survey, data were collected on each participant's age, gender, religion, ethnicity, marital status, family size, education, occupation and monthly income.

\section{Psychiatric morbidity}

At baseline and follow-up, mental health status was ascertained using the CIDI 2.1, a fully structured instrument produced by the WHO and for use across cultures (Sartorius \& Janca, 1996). Translation and back-translation from English to Amharic were completed using standard WHO guidelines. CIDI was evaluated in patient and community samples and reported to perform well (Rashid et al, 1996), and has been used in several studies (Kebede et al 1999; Kebede et al, 2003a,b).

At follow-up we also used the Self Reporting Questionnaire (SRQ-20; World Health Organization, 1994), an instrument developed by the WHO to detect mental health problems in primary healthcare attendees in low-income countries. Our aim was to identify persistent psychiatric morbidity that did not meet criteria for major depression. SRQ-20 identifies symptoms mainly related to anxiety and depression. It has previously been validated (Kortmann, 1988) and used in several surveys in Ethiopia (Alem et al, 1999; Kebede et al, 1999). 


\section{Definitions}

Major depression was defined according to DSM-IV criteria (American Psychiatric Association, 1994). Since the incident cases of major depression (in the last 12 months) at follow-up were very few $(n=5)$ this group was excluded from the analysis. There were subsequently 3 groups chosen for comparison. The no depression group included participants with no depression either at baseline or within the 12 months preceding the follow-up assessment. The recovered depression group included participants with major depression at baseline but not within the 12 months preceding the follow-up assessment. This group was further divided into partially recovered (SRQ scores above the cut point) and completely recovered (SRQ scores below the $5 / 6$ cut point). The persistent depression group included participants with major depression both at baseline and within the past 12 months preceding the follow-up assessment.

Information on the reason for loss to follow-up (for example moved away, died) was obtained from family members and local community leaders.

\section{Disability}

The 36-item fully structured intervieweradministered version of the World Health Organization Disability Assessment Schedule (WHODAS-II) was used at follow-up. WHODAS-II assessed the level of disability and the number of days lost from work in the past 30 days. This measure was developed with a view to cross-cultural validity and applicability across a spectrum of educational backgrounds (Vázquez-Barquero et al 2000; Chwastiak et al, 2003). Two disability outcomes were assessed.

Disability days referred to the proportion of those reporting more than 15 disability days lost from work and normal activities in the past month. Disability scores assessed day-to-day functioning in six activity domains: understanding and communicating, getting around, self-care, getting along with people, life activities and participation in society. Results provided a profile of functioning within the domains as well as overall score. Weighted scores ranged from 0 to 100 , with higher scores reflecting greater disability.

\section{Use of health services}

A modified version of the Client Service Receipt Inventory (Chisholm et al, 2000a) was used to collect data on contact with health care services in the past 3 months. This questionnaire was devised for use in low- and middle-income countries (Chisholm et al, 2000b), and elicits information on primary healthcare visits, in-patient admission and consultation with private practitioners, including local healers, as well as medications and investigations provided as part of care.

The WHODAS-II and Client Service Receipt Inventory were forward-translated into Amharic and then back-translated to English for this study. The two versions were sent to Ethiopia to be examined by a panel of bilingual experts. Rewording of some of the items was carried out, and the measures were finally re-examined by a bilingual mental health researcher in Ethiopia.

\section{Procedure}

Five data collectors and a coordinator, experienced in the use of CIDI, were recruited from the district and trained in the use of additional fully structured assessments. Community leaders were approached to identify study subjects. All interviews were conducted in participants' homes over a 4month period in 2002. Interviewers were masked to the participant's baseline status. Data were then entered onto Epi Info ${ }^{\mathrm{TM}}$ (a series of computer programs for analysis of epidemiological data developed by the US Centers for Disease Control and Prevention) and CIDI data entry programs.

The study was reviewed and approved by the research ethics committees in the Institute of Psychiatry and the Department of Community Health in Addis Ababa University. After complete description of the study, informed consent was obtained from all participants.

\section{Analysis}

Data were analysed using SPSS 11.0 software. Three participants from the no depression group and 5 from the major depression group, who could not be matched confidently with baseline data were excluded from further analysis.

Proportions and rate ratios with $95 \%$ CI were used to compare mortality, disability days and health service use between the groups. Total and domain-specific WHODAS-II scores were treated as individual continuous dependent variables. The WHODAS-II score was skewed, and so median and interquartile ranges were computed for each outcome group to describe the distribution. A non-parametric Mann-Whitney $U$-test compared score distributions between the outcome groups, two-tailed tests were used and $P$-values presented. The generalised linear model (GLM) assessed variance of WHODAS-II score (log-transformed) explained by depression status at follow-up, adjusting for age, gender and socioeconomic status and partial eta-squared value given. The Scheffé test compared the different outcome groups.

\section{RESULTS}

\section{Characteristics of participants selected for follow-up}

Most participants were farmers or housewives, earning less than $100 \mathrm{Birr} /$ month (equivalent to US $\$ 18 /$ month) (Table 1 ). Major depression at baseline was significantly associated with male gender $\left(\chi^{2}=5.2,1\right.$ d.f., $\left.P=0.02\right)$ and older age $\left(\chi^{2}=13.5\right.$, 1 d.f., $\left.P=0.000\right)$, but not with occupation or monthly income.

\section{Follow-up}

Of 600 participants, 423 were reinterviewed between 18 and 52 months after baseline, giving an overall follow-up proportion of $70.5 \%$. This proportion was similar to the proportion of those with no depression $(71.0 \%)$ and with major depression $(70.0 \%)$ at baseline. The reasons for loss to follow-up were also similar between these groups, except for the proportions known to have died (see below under impact of depression). Overall loss to follow-up was significantly higher in the $15-19$ years' age group $(37.1 \%)$, in people who were not from major tribal groups in Butajira $(38.3 \%)$, in those who had never been married $(40.8 \%)$ and in those with no children $(38.5 \%)$.

\section{Major depression at follow-up}

Among the 210 participants with no depression at baseline, $5(2.4 \%)$ had major depression at the time of the follow-up assessment or within the previous 12month period (incident major depression), and these were excluded from subsequent analyses. The remaining 205 participants $(97.6 \%)$ had no significant depressive symptoms at the time of the follow-up assessment, or within the previous 12month period (no depression). However, there were 9 participants $(4.3 \%)$ who had 
Table I Baseline sociodemographic characteristics of patients selected for follow-up

\begin{tabular}{lccc}
\hline Characteristic & $\begin{array}{c}\text { No depression } \\
n=300\end{array}$ & $\begin{array}{c}\text { Major depression } \\
n=300\end{array}$ & $\begin{array}{c}\text { Total } \\
n=600\end{array}$ \\
& $n(\%)$ & $n(\%)$ & $n(\%)$ \\
\hline Gender & & & \\
Female & $155(51.7)$ & $127(42.3)$ & $282(47.0)$ \\
Male & $145(48.3)$ & $173(57.7)$ & $318(53.0)$ \\
Age group (years) & & & \\
I5-19 & $74(24.7)$ & $31(10.3)$ & $105(17.5)$ \\
$20-29$ & $94(31.3)$ & $113(37.7)$ & $207(34.5)$ \\
$30-39$ & $84(28.0)$ & $85(28.3)$ & $169(28.2)$ \\
$40-49$ & $48(16.0)$ & $71(23.7)$ & $119(19.8)$ \\
Occupation & & & \\
Farmer & $115(38.3)$ & $128(42.7)$ & $243(40.5)$ \\
Housewife & $86(28.7)$ & $63(21.0)$ & $149(24.8)$ \\
Other' & $99(33.0)$ & $109(36.3)$ & $208(34.7)$ \\
Monthly income (Birr/month) & & & \\
None & $83(27.7)$ & $89(29.7)$ & $172(28.7)$ \\
I-100 & $163(54.3)$ & $156(52.0)$ & $319(53.2)$ \\
I0I-200 & $41(13.7)$ & $46(15.3)$ & $87(14.5)$ \\
$>201$ & $13(4.3)$ & $9(3.0)$ & $22(3.7)$ \\
Followed-up (\%) & & & \\
Yes & $213(71.0)$ & $210(70.0)$ & $423(70.5)$ \\
No & $87(29.0)$ & $90(30.0)$ & $177(29.5)$ \\
\hline I. & & & \\
\hline
\end{tabular}

I. Includes student, daily labourers, government employee and small traders.

major depression after baseline assessment but before the 12-month follow-up assessment. Among the 205 participants with major depression at baseline, $54(26.3 \%)$ had major depression at the time of the follow-up assessment, or within the previous 12-month period (persistent major depression), $27(13.2 \%)$ had no major depression at follow-up but did have more than 5 SRQ symptoms (partially recovered), and the remaining 124 $(60.5 \%)$ had no significant depressive symptoms (completely recovered).

\section{Methodological factors influencing outcome}

Among those with major depression there was no association between outcome status and mean duration of follow-up, which for those with persistent major depression was 30.1 months (s.d.=9.3 months), and for those partially or completely recovered was 32.7 months (s.d.=11.0 months), a mean difference of 2.5 months $195 \%$ CI -0.5 to 5.6 months). According to the protocol of the Butajira baseline study, all participants with major depression that was subsequently confirmed by clinicians Schedules for Clinical Assessment in
Neuropsychiatry (SCAN) interview were offered tricyclic antidepressants, primarily amytriptyline. However, compliance was poor, with only $25 \%$ remaining in contact for half or more of the follow-up period. Of the cases of major depression included in this follow-up, $42(20.5 \%)$ were clinically confirmed using SCAN in the baseline phase. The outcome, measured as persistence of depression, was worse in SCANpositive cases (rate ratio 2.11, 95\% CI 1.35-3.28).

\section{The impact of major depression and subclinical symptoms \\ Mortality}

Over the follow-up period, $2(0.7 \%)$ of the participants with no depression and 9 $(3.0 \%)$ of the participants with major depression were reported to have died. The mortality ratio standardised for age and gender was 3.55 (95\% CI 1.97-6.39).

\section{Disability days}

Within the 30 days preceding the follow-up assessment, 15 or more disability days were reported by $14(6.8 \%)$ of those with no depression, $6(4.8 \%)$ of those with completely recovered depression, by 13 $(48.1 \%)$ of those with partly recovered depression and $24(44.4 \%)$ of those with persistent depression. The prevalence ratio for those with persistent depression, compared with those with no depression, was 6.51 (95\% CI 3.62-11.71). There was no significant difference between the group with persistent depression and the partially recovered group (prevalence ratio 0.92; 95\% CI 0.50-1.51), or between those with no depression and the completely recovered group (prevalence ratio 0.71; 95\% CI 0.28-1.80).

\section{Disability}

WHODAS-II disability scores were positively skewed in all groups. The median (and interquartile range) was $0.0(0.0-0.0)$ for those who were not depressed, 0.0 (0.0-5.4) for those who had recovered and $19.8(0.0-44.8)$ for those with persistent depression. Disability scores were significantly higher in the recovered group than in those with no depression (MannWhitney $U$-test; $Z=-3.5, P=0.001$ ), and in those with persistent depression compared with those who had recovered (Mann-Whitney $\quad U$-test; $Z=-5.8$, $P<0.001)$. After $\log$ transformation of the overall WHODAS disability score, using a Scheffé test to account for multiple between-group comparisons, the group with persistent depression did not differ significantly from the partially recovered group $(P=0.27)$. However, both the group with persistent depression $(P<0.0001)$ and the partially recovered group $(P=0.004)$ were significantly more impaired than the completely recovered group. Depression status at follow-up explains $27.5 \%$ (partial eta squared) of the variance in WHODAS-II without adjustment, and $26.6 \%$ when adjusted for age, gender and income.

Individual disability domain scores were significantly greater for those with persistent depression than for those who had completely recovered in all 6 domains of functioning (Mann-Whitney $U$-test, $P<0.001$ ). Further analysis, within the recovered group, identified no significant difference in the profile of domain scores between those with persistent depression and the partially recovered, other than mobility disability, which was higher in the partially recovered $(P=0.02)$, and disability in getting on with others, which was greater in the group with persistent 
Table 2 WHODAS-II total and domain-specific scores by clinical outcome status

\begin{tabular}{|c|c|c|c|c|}
\hline Clinical outcome status & $\begin{array}{c}\text { Never depressed } \\
\quad(n=205) \\
\text { Mean, median (IQR) }\end{array}$ & $\begin{array}{l}\text { Completely recovered } \\
\qquad(n=124) \\
\text { Mean, median (IQR) }\end{array}$ & $\begin{array}{l}\text { Partially recovered } \\
\qquad(n=27) \\
\text { Mean, median (IQR) }\end{array}$ & $\begin{array}{l}\text { Persistently depressed } \\
\qquad(n=54) \\
\text { Mean, median (IQR) }\end{array}$ \\
\hline \multicolumn{5}{|l|}{ WHODAS-II domain } \\
\hline Understanding & $2.1,0.0(0.0-0.0)$ & $0.73,0.0(0.0-0.0)$ & I6.I, $\quad 0.0(0.0-0.0)$ & $27.4,20.0(0.0-55.0)$ \\
\hline Mobility & $2.4,0.0(0.0-0.0)$ & $2.5, \quad 0.0(0.0-0.0)$ & $24.3,12.5(0.0-43.8)$ & $13.0, \quad 0.0(0.0-14.06)$ \\
\hline Self-care & $0.5,0.0(0.0-0.0)$ & $0.2, \quad 0.0(0.0-0.0)$ & $0.7, \quad 0.0(0.0-0.0)$ & $6.5, \quad 0.0(0.0-0.0)$ \\
\hline Getting on with others & $0.5,0.0(0.0-0.0)$ & $0.8, \quad 0.0(0.0-0.0)$ & $0.6, \quad 0.0(0.0-0.0)$ & $16.8,0.0(0.0-18.8)$ \\
\hline Life activity & $7.2,0.0(0.0-0.0)$ & $5.5, \quad 0.0(0.0-0.0)$ & $47.8,50.0(0.0-80.0)$ & $40.6,35.0(0.0-90.0)$ \\
\hline Participation & $3.8,0.0(0.0-0.0)$ & $3.3,0.0(0.0-0.0)$ & $32.0,35.0(0.0-50.0)$ & $37.9,30.0(0.0-66.3)$ \\
\hline Total score & $2.7,0.0(0.0-0.0)$ & $2.1, \quad 0.0(0.0-0.0)$ & $20.5,21.5(7.6-21.7)$ & 24.7, $19.6(0.0-44.8)$ \\
\hline \multicolumn{5}{|l|}{ Using healthcare provision (\%) } \\
\hline Government primary care & 6.3 & 8.9 & 7.4 & 16.7 \\
\hline Private healthcare & 6.8 & 4.0 & 3.7 & 9.3 \\
\hline Traditional healer & 0.5 & 4.0 & II.I & 7.4 \\
\hline Any health service & 12.2 & 16.1 & 22.2 & 33.4 \\
\hline
\end{tabular}

IQR, interquartile range; WHODAS-II, World Health Organization Disability Assessment Schedule.

depression $(P=0.003)$. The partially recovered group had significantly more disability $(P<0.001)$ than the completely recovered group in all domains of WHODAS-II except in self care and getting on with others, which were not statistically significant.

\section{Use of health services}

Only 25 of those with no depression $(12.2 \%), 20$ of the completely recovered $(16.1 \%), 6$ of the partially recovered $(22.2 \%)$ and 18 of those with persistent depression $(33.4 \%)$ had used health services of any kind in the 3 months before follow-up assessment (Table 2). Those with persistent major depression were more likely to have used services than those who had recovered (prevalence ratio 1.94, 95\% CI 1.16-3.24) and than those who were not depressed (prevalence ratio 2.73, 95\% CI 1.61-4.63). The difference between the recovered and those with no depression was not statistically significant (prevalence ratio $1.41,95 \%$ CI $0.85-$ 2.34). There was no significant difference between the group with persistent depression and the partially recovered group (prevalence ratio $1.50,95 \%$ CI $0.67-3.34$ ) or between the completely recovered and those with no depression (prevalence ratio $1.32,95 \%$ CI $0.77-2.28$ ).

Among participants with persistent major depression, $9(16.7 \%)$ had used government primary healthcare services, 5
$(9.3 \%)$ private healthcare, and $4(7.4 \%)$ traditional and religious healers. However, two-thirds had not used any service.

\section{DISCUSSION}

We believe this to be the first populationbased study of the clinical outcome, impact and patterns of help seeking associated with depression in sub-Saharan Africa. Of those with major depression at baseline, $26 \%$ had this diagnosis at follow-up 2 to 4 years later. This figure is similar to estimates from high-income countries (Sargeant et al, 1990; Spijker et al, 2001), although very few of our group with depression accessed any form of healthcare. Persistent depression was associated with a greater likelihood of experiencing more than 15 disability days in the month, higher disability scores and greater use of health services compared with recovered from or absence of depression. Complete recovery from depression was associated with a pattern of disability and health service use similar to absence of depression, whereas participants with residual subclinical symptoms resembled, in these respects, those with persistent major depression.

This study does have some limitations. First, the baseline prevalence of major depression from the original population survey (694 out of 56441 or $1.2 \%$ ) is lower than in similar studies in high-income countries. However, a similarly low prevalence has also been reported in other sub-Saharan African countries (World Health Organization World Mental Health Survey Consortium, 2004). This finding could reflect a limitation of CIDI performance in this part of the world, where there is much illiteracy; mental health constructs and the phrases used to describe them may not be well understood. There may of course be a genuinely low prevalence in this region where, although there is much economic hardship, there is a strong and stable social structure. Second, our classification of outcome status was based on 12month prevalence estimated at a single follow-up assessment, which may have missed fluctuations in clinical state over the whole follow-up period. Third, the attrition rate was $30 \%$. We felt that the response rate of $70 \%$ was acceptable, considering the time interval between initial assessment and follow-up and the difficulty of home visits over a very large rural area. Change of address was the main reason for loss to follow-up, which was significantly higher among the young, the never married, those with no income and those not from the major ethnic group in the district; these participants may have been temporary residents who came for work during harvest periods and left in search of better opportunities. The response rate and the reason for non-response were similar across the study groups, but the likely effect of non-response upon outcome is hard to predict. Those who migrate for work are 
often relatively healthy. The variability in length of follow-up is also a limitation of this study; however, its effect on outcome status was not found to be significant.

Mortality was ascertained from close family members and community leaders, as there was no record-keeping system in place. Of our sample, $8 \%$ could not be traced and key informants had no knowledge of their vital status. This is a limitation, but there is little chance of information bias, since the follow-up data collectors were masked to baseline group status. The observed mortality in the group with major depression was more than 3.5 times higher than expected from the mortality of those with no depression, after standardising for age and gender. This is the first time, to our knowledge, that such a finding has been reported from a highmortality, low-income country setting. Epidemiological research among older people in the developed nations suggests a consistent independent association between depression and mortality (Penninx et al, 1999; Abas et al, 2002). The strong association observed in the relatively young population studied here underlines the seriousness of major depression. Physical illness, unfortunately not measured directly in this study, is an important covariate likely to be associated with depression, with complex bidirectional pathways (Prince, 1998). Thus, the high mortality rate among individuals with depression may be explained by physical comorbidity, suicide or accidental death; cause of death could not be estimated with sufficient certainty to be incorporated in our analysis.

Major depression was strongly associated with disability. Nearly $50 \%$ of those with persistent depression at follow-up had lost more than half of the days in the previous month to disability (disability days). This burden of disability is much higher than in similar studies in highincome countries, perhaps because of the chronicity of depression in this community where the accessibility of care is very low. Such disability implies a major economic effect upon the family and the community at large. The completely recovered group had a similar disability status to those without depression indicating that spontaneous clinical recovery is associated with concurrent good functional recovery. This is an encouraging indication that the introduction of more effective and accessible care for those with major depression might have an important practical and economic impact. Our study supports findings from clinical settings in high-income countries, that disability resolves with clinical symptoms (Von Korff et al, 1992; Simon et al, 2000). A pattern of increments in psychosocial disability associated with different levels of depression severity has been observed in studies of clinical populations in high-income countries (Ormel et al, 1993; Judd et al, 2000). However, in our study the partially recovered group showed a similar disability status to the group with persistent depression, even though they did not fulfil the diagnostic criteria for major depression.

We observed low levels of health service use, for both biomedical and traditional services, across the groups studied. The main reason could be lack of recognition of the seriousness of mental illness and lack of understanding about the potential benefit of consultation. A previous key informant case vignette study in Ethiopia reported that depression was regarded as the least serious mental disorder with the lowest rank order in perceived frequency of occurrence (Alem et al, 1999). The cost of private biomedical and traditional healer services is relatively high, and the opportunity costs (time off work) associated with the use of government services may also be a deterrent. Although the frequency of service use was generally about twice as high and among those with persistent depression at followup compared with those who had recovered, the large majority of those with persistent major depression had not contacted any provider in the past 3 months despite the significant disability they experienced in the same period. Our population-based study provides a different perspective from that of previous research in sub-Saharan Africa, which has tended to focus upon participants recruited in primary care. Studies in Zimbabwe (Patel et al, 1997) and Tanzania (Ngoma et al, 2003) have drawn attention to the high prevalence of mental disorder in primary care, particularly among attendees in traditional healer clinics. However, it appears, at least in Butajira, that help seeking is unusual in the community, even with serious and chronic depression. Traditional healers are rarely consulted. The impermeability of the first filter between the incidence of the condition in the community and seeking help is therefore a key issue that should be addressed. Much more information is needed regarding the characteristics, beliefs, knowledge and illness attributes of those who are and those who are not inclined to seek help. The current study suggests that a considerable burden of mortality, disability and unmet need is associated with major depression. Future research needs to make more apparent the important links between existing health priorities and mental disorders.

\section{ACKNOWLEDGEMENTS}

Mr Endalkachew Haile back-translated the instruments, and Dr Negussie Deyessa supported data management. We also thank the Mental Health Project staff in Ethiopia for their support, and the community of Butajira for their full cooperation. The Wellcome Trust Tropical Medicine Panel funded data collection.

\section{REFERENCES}

Abas, M., Hotopf, M. \& Prince, M. (2002) Depression and mortality in a high-risk population. II-Year follow-up of the Medical Research Council Elderly Hypertension Trial. British Journal of Psychiatry, 18I, 123-128.

Alem, A., Jacobsson, L., Araya, M., et al (1999) How are mental disorders seen and where is help sought in a rural Ethiopian community? A key informant study in Butajira, Ethiopia. Acta Psychiatrica Scandinavica, 100, 40-47.

Alem, A., Kebede, D., Woldesemiat, G., et al (1999) The prevalence and socio-demographic correlates of mental distress in Butajira, Ethiopia. Acta Psychiatrica Scandinavica, 100, 48-55.

American Psychiatric Association (1994) Diagnostic and Statistical Manual of Mental Disorders (4th edn) (DSM-IV). Washington, DC: APA.

Central Statistics Authority (2000) Statistical Abstract of Ethiopia. Addis Ababa, Ethiopia: Central Statistics Authority.

Chisholm, D., Knapp, M. R., Knudsen, H. C., et al (2000a) Client Socio-Demographic and Service Receipt Inventory-European Version: development of an instrument for international research. EPSILON Study 5. British Journal of Psychiatry, I7I (suppl. 39), s28-s33.

Chisholm, D., Sekar, K., Kumar, K. K., et al (2000b) Integration of mental health care into primary care. Demonstration cost-outcome study in India and Pakistan. British Journal of Psychiatry, 176, 58I-588.

Chwastiak, L. A. \& Von Korff, M. (2003) Disability in depression and back pain. Mutation of the World Health Organization Disability Assessment Schedule (WHO DAS II) in a primary care setting. Journal of Clinical Epidemiology, 56, 507-5I4.

Ethiopian Ministry of Health (2002) Health and Health Related indicators. Addis Ababa, Ethiopia: Planning and Programming Department, $\mathrm{FMOH}$.

Judd, L. L., Akiskal, H. S., Zeller, P. J., et al (2000) Psychosocial disability during the long-term course of unipolar major depressive disorder. Archives of General Psychiatry, 57, 375-380. 
Kebede, D. \& Alem, A. (1999) Major mental disorders in Addis Ababa, Ethiopia. II. Affective disorders. Acto Psychiatrica Scandinavica, 100, 18-23.

Kebede, D., Alem, A., Rashid, E. (1999) The prevalence and socio-demographic correlates of mental distress in Addis Ababa, Ethiopia. Acta Psychiatrica Scandinavica, 100, 5-10.

Kebede, D., Alem, A., Deyassa, N., et al (2003a) Socio-demographic correlates of depressive disorder in Butajira, rural Ethiopia. Central African Journal of Medicine, 49, 78-83.

Kebede, D., Alem, A., Shibre, T., et al (2003b) Onset and clinical course of schizophrenia in Butajira-Ethiopiaa community-based study. Social Psychiatry and Psychiatric Epidemiology, 38, 625-631.

Kessler, R. C., Berglund, P., Demler, O., et al (2003) The epidemiology of major depressive disorder: results from the National Comorbidity Survey Replication (NCS-R). JAMA, 289, 3095-3105.

Kortmann, F. (1988) Problems in practicing psychiatry in Ethiopia. Ethiopian Medical Journal, 26, 76-84.

Lee, A. S. \& Murray, R. M. (1988) The long-term outcome of Maudsley depressives. British Journal of Psychiatry, I53, 741-751.

Lepine, J. P., Gastpar, M., Mendlewicz, J., et al (1997) Depression in the community: the first pan-European study DEPRES (Depression Research in European Society). International Clinical Psychopharmacology, 12 19-29.

Murray, C. J. L. \& Lopez, A. D. (1996) The Global Burden of Disease. A comprehensive assessment of mortality and disability from disease, injuries and risk factors in 1990 and projected to 2020. Harvard, IL: Harvard University.

Ngoma, M. C., Prince, M. \& Mann, A. (2003) Common mental disorders among those attending primary health clinics and traditional healers in urban Tanzania. British Journal of Psychiatry, 183, 349-355.

\section{Office of Population and Housing Census} Commission (1994) The 1994 Peoples Region Housing census of Ethiopia. Results for Southern Nations, Nationalities and Peoples. Region abridged statistical report. Addis Ababa: Ministry of Health.

SOUCI MOGGA, MD, MPH, MARTIN PRINCE, MD, MSc, MRCPsych, Institute of Psychiatry, London, UK; ATALAY ALEM, MD, PhD, Department of Psychiatry, Addis Ababa University, Ethiopia; DEREGE KEBEDE, MD, DSc, Department of Community Health, Addis Ababa University, Ethiopia; ROBERT STEWART, MD, MSc, MRCPsych, NICK GLOZIER, MSc, MRCPsych, MATTHEW HOTOPF, BSc, MBBS, MRCPsych, MSc, PhD, Institute of Psychiatry, London, UK

Correspondence: Dr Souci Mogga Frissa, Institute of Psychiatry, De Crespigny Park, London SE5 8AF, UK.Email: S.Frissa@iop.kcl.ac.uk

(First received 23 May 2005, final revision 20 September 2005, accepted I December 2005)

Ormel, J., Von Korff, M., Brink, W. V. D., et al (1993) Depression, anxiety and social disability show synchrony of change in primary care patients. American Journal of Public Health, 83, 385-390.

Patel, V., Todd, C., Winston, M., et al (1997) Common mental disorders in primary care in Harare, Zimbabwe: associations and risk factors. British Journal of Psychiatry, I7I, 60-64.

Penninx, B.W., Geerlings, S. W., Deeg, D. J., et al (1999) Minor and major depression and the risk of death in older persons. Archives of General Psychiatry, 56, 889-895.

Prince, M. J. (1998) The classification and measurement of disablement, with emphasis on depression, and its applications for clinical gerotology. Reviews in Clinical Gerontology, 8, 227-240.

Rashid, E., Kebede, D. \& Alem, A. (1996) Evaluation of an Amharic version of the Composite International Diagnostic Interview (CIDI) in Ethiopia. Ethiopian Journal of Health Development, 10, 69-77.

Sargeant, J. K., Bruce, M. L., Florio, L. P., et al (1990)

Factors associated with I-year outcome of major depression in the community. Archives of General Psychiatry, 47, 519-526.

Sartorius, N. \& Janca, A. (1996) Psychiatric assessment instruments developed by the World Health Organization. Social Psychiatry and Psychiatric Epidemiology, 3I, 55-69.

Simon, G. E., Revicki, D., Heiligenstein, J., et al (2000) Recovery from depression, work productivity, and health care costs among primary care patients. General Hospital Psychiatry, 22, I53-162.

Spijker, J., Bijl, R.V., de Graaf, R., et al (200I) Determinants of poor I-year outcome of DSM-III-R major depression in the general population: results of the Netherlands Mental Health Survey and Incidence Study (NEMESIS). Acta Psychiatrica Scandinavica, 103. 122-130.

Vázquez-Barquero, J. L., Vázquez, B. E., Herrera, C. S., et al (2000) World Health Organization Disability Assessment Schedule II (WHO-DAS-II): initial phase of development and pilot study. Cantabria Disability Work Group (Spanish). Actas Espanolas de Psiquiatria, 28(2), 77-87.

Von Korff, M., Ormel, J., Katon, W., et al (1992) Disability and depression among high utilizers of health care. A longitudinal analysis. Archives of General Psychiatry, 49, 91-100.

World Health Organization (1994) A User Guide to the Self Reporting Questionnaire (SRQ). Geneva: WHO.

World Health Organization (1997) Composite International Diagnostic Interview (CIDI). Version 2.I. Geneva: WHO.

World Health Organization World Mental Health Survey Consortium (2004) Prevalence, severity, and unmet need for treatment of mental disorders in the World Health Organization World Mental Health Surveys. JAMA, 29I, 258I-2590. 